\title{
MEG3 regulates apoptosis of adipose-derived stem cells
}

\author{
YAO SHI \\ Department of Breast Surgery, The First Hospital of China Medical University, Shenyang, Liaoning 110001, P.R. China
}

Received July 31, 2019; Accepted March 18, 2020

DOI: $10.3892 / \mathrm{mmr} .2020 .11059$

\begin{abstract}
In plastic surgery, the maneuverability and safety of autologous fat transplantation have become increasingly recognized and continuously improved. However, the uncertainty of adipocyte survival makes it difficult to predict postoperative effects. Adipose-derived stem cells (ADSCs) exhibit remarkable paracrine activity, and the number of ADSCs in adipose tissue is closely related to tissue survival. Maternally expressed gene 3 (MEG3) is known to modulate the apoptosis of various cell types. The present study aimed to evaluate the hypothesis that MEG3 serves an important role in ADSC apoptosis by regulating the expression of p53, and to explore the regulatory mechanisms of p53 in ADSC apoptosis. MEG3 was overexpressed in ADSCs and these cells were evaluated for viability, TP53 expression, apoptosis, morphology, and Bax and Bcl-2 expression by performing MTT assays, reverse transcription-quantitative PCR, flow cytometry analysis and western blotting. This study demonstrated that MEG3 may have an important role in the spontaneous apoptosis of ADSCs, and apoptosis induced by oxidative stress. In addition, this study revealed that p53 had a regulatory role in the downstream Bcl-2/Bax pathway. This study provides insight into the role of MEG3 in ADSC apoptosis, thereby facilitating the survival of ADSCs during adipose tissue transplantation. Further in vivo and in vitro experiments should be conducted, along with the development of clinical applications.
\end{abstract}

\section{Introduction}

Autologous adipocyte transplantation is increasingly applied in plastic surgery because of its numerous advantages (1). Autologous adipocytes were initially used as filling material to permanently maintain morphological features after

Correspondence to: Dr Yao Shi, Department of Breast Surgery, The First Hospital of China Medical University, 155 Nanjing Bei Street, Shenyang, Liaoning 110001, P.R. China

E-mail: drshiy@126.com

Abbreviations: ADSC, adipose-derived stem cell; TBST, Tris-buffered saline-Tween

Key words: adipose tissue, autologous transplantation, adiposederived stem cells, MEG3, p53, apoptosis successful transplantation; the morphology of such tissues is natural and resembles that of normal tissue. Liposuction is a simple surgical method that can easily yield large amounts of adipose tissue from numerous body regions to satisfy various tissue requirements (2). Furthermore, because the tissue is derived from the patient, immune rejection, allergic reactions and tissue toxicity exhibited towards some artificial materials do not occur (3). In addition, in the long term, adipose tissue is a relatively safe tissue-filling substance (4). However, after autologous fat transplantation, autologous tissue can become necrotic and is reabsorbed over time. The survival rate of autologous adipocytes is only $20-70 \%$ of the intraoperative filling volume $(4,5)$. The reduction in tissue volume often leads to depressions, asymmetric morphology and even failure of the surgical filling. To achieve the desired filling effects, the patient may need to undergo multiple operations.

Mechanical damage to the adipose tissue that has been extracted can occur during liposuction, which results in necrosis and loss of the transplanted tissue. The lack of vascular reconstruction in the transplanted adipose tissue also affects the survival rate of adipocytes (6,7). Billings et al (8) first reported that 'fibroblast-like' mesenchymal cells in the adipose tissue may facilitate adipose tissue survival. Adipose-derived stem cells (ADSCs) are mesodermal cells derived from adipose tissues. Their morphology is fusiform, and they can differentiate into adipose, bone, cartilage, muscle, epithelial, neuronal and other tissue types. Previous studies investigating the use of stem cell transplantation to treat tissue injury have reported that stem cells promote tissue repair $(2,3,9)$. Furthermore, an increasing number of studies have reported that the paracrine signaling from stem cells is an important mechanism that promotes various physiological activities in cells $(10,11)$. Various cellular factors secreted by ADSCs are involved in forming and regenerating blood vessels, and significantly improve the survival rate of adipocytes $(12,13)$. Studies also reported that increasing the number of ADSCs in adipose tissue can significantly promote the survival rate of adipose tissue (14). Abundant ADSCs can be obtained during liposuction; however, mechanical damage during adipose tissue extraction, ischemia and hypoxia in the tissue, cell rupture and death, and the release of numerous reactive oxygen species can lead to oxidative stress and finally apoptosis (15). Understanding the mechanism underlying the induction of apoptosis of ADSCs may lead to the development of methods for decreasing their apoptotic rate and increasing their numbers in tissues, which would help to improve the survival rate of transplanted adipose tissue. 
Maternally expressed gene 3 (MEG3) is a long non-coding RNA (lncRNA) (1.6 kb) expressed in normal human tissues but frequently downregulated in tumor cells (16). MEG3 overexpression has been reported to promote apoptosis in various tissues and cells; however, the mechanism of action of MEG3 in ADSCs is unclear (17-20). Some studies have reported that MEG3 may influence apoptosis through activation of p53, which in turn regulates downstream genes $(21,22)$. Tumor suppressor p53 regulates cell cycle initiation and contributes to apoptosis, genomic stability and angiogenesis. Upon irreversible DNA damage, p53 triggers apoptosis. The present study evaluated the roles of MEG3 and p53 in apoptosis of ADSCs by analyzing the expression of p53 and its related downstream molecules.

\section{Materials and methods}

Cell culture. Human ADSCs were purchased from the Cell Bank of the Shanghai Institutes for Biological Sciences. Cells were cultured in DMEM (Gibco; Thermo Fisher Scientific, Inc.) containing $10 \%$ fetal bovine serum (Gibco; Thermo Fisher Scientific, Inc.) and $100 \mathrm{U} / \mathrm{ml}$ penicillin/streptomycin (Gibco; Thermo Fisher Scientific, Inc.). Cells were incubated at $37^{\circ} \mathrm{C}$ in a humidified chamber with $5 \% \mathrm{CO}_{2}$. Cells were harvested using $0.25 \%$ trypsin- $0.02 \%$ EDTA solution (Gibco; Thermo Fisher Scientific, Inc.) and sub-cultured to $80 \%$ confluence. A cell oxidative stress model was established by incubating cells with $130.6 \mu \mathrm{M} \mathrm{H}_{2} \mathrm{O}_{2}$ at $37^{\circ} \mathrm{C}$ for $24 \mathrm{~h}$. Cells cultured in normal medium were used as a control group.

Transfection. The MEG3 sequence was synthesized (GenBank NR_002766) and subcloned into the pCDNA3.1 vector (Shanghai GeneChem Co., Ltd.). MEG3 was ectopically expressed by transfection of pCDNA-MEG3. The empty pCDNA vector was used as a control. The small interfering (si)RNA targeting MEG3 (forward, 5'-GGUUGUUGUGAG AAUUAAAUG-3' and reverse, 5'-UUUAAUUCUCACAAC AACCCU-3') and its negative control (NC; forward, 5'-GGU AAUGUUAAUGAGUUGAUG-3' and reverse, 5'-UCCCAU UACAAUUACUCAACU-3') were purchased from Shanghai GeneChem Co., Ltd. ADSCs were seeded $\left(0.5 \times 10^{5}\right.$ cells/well $)$ into 24-well plates and cultured at $37^{\circ} \mathrm{C}$ for $24 \mathrm{~h}$. At $90 \%$ confluence, cells were transfected with pCDNA3.1 vectors $(2 \mathrm{mg} / \mathrm{l})$ or siRNAs $(40 \mathrm{nmol} / \mathrm{l})$ using Lipofectamine ${ }^{\circledR} 2000$ (Invitrogen; Thermo Fisher Scientific, Inc.), according to the manufacturer's protocol. At $24 \mathrm{~h}$ post-transfection, subsequent experiments were performed.

Cell viability assay. Cell viability was assessed using an MTT assay. Cells $\left(0.1 \times 10^{5}\right.$ cell/well) were seeded in 96-well plates for $24 \mathrm{~h}$. Cells were pretreated with different concentrations of $\mathrm{H}_{2} \mathrm{O}_{2}(0-300 \mu \mathrm{M})$ at $37^{\circ} \mathrm{C}$ for $24 \mathrm{~h}$. Subsequently, $10 \mu \mathrm{l}$ MTT $(5 \mathrm{mg} / \mathrm{ml})$ solution was added to each well and incubated for $4 \mathrm{~h}$ at $37^{\circ} \mathrm{C}$. To dissolve the formazan crystals, $150 \mu \mathrm{l}$ DMSO was added to each well. The absorbance of each well was measured at a wavelength of $490 \mathrm{~nm}$ using a microplate reader (Thermo Fisher Scientific, Inc.). Data are expressed as percentages of the untreated control.

$R N A$ extraction and reverse transcription-quantitative $P C R$ $(R T-q P C R)$ analysis. Total RNA was isolated using TRIzol ${ }^{\circledR}$ reagent (Invitrogen; Thermo Fisher Scientific, Inc.), according to the manufacturer's protocol. Toral RNA was reverse transcribed into cDNA using Super M-MLV Reverse Transcriptase and 2xPower Taq PCR MasterMix (Bioteke Corporation), according to the manufacturer's protocol. Briefly, for RT, $1 \mu \mathrm{l}$ oligo (dT) $)_{15}$ and $2 \mu \mathrm{ldNTPs}(2.5 \mathrm{mM}$ each) were added, and then $\mathrm{ddH}_{2} \mathrm{O}$ was added to a total volume of $14.5 \mu \mathrm{l}$. The following thermocycling conditions were used for reverse transcription: $10 \mathrm{~min}$ at $25^{\circ} \mathrm{C}, 50 \mathrm{~min}$ at $42^{\circ} \mathrm{C}$ and $5 \mathrm{~min}$ at $95^{\circ} \mathrm{C}$. The both forward and reverse primers for MEG3, TP53 and $A C T B$ were provided by Shanghai GenePharma Co., Ltd. (Table I).

qPCR was performed using the following thermocycling conditions: Initial denaturation at $95^{\circ} \mathrm{C}$ for $3 \mathrm{~min} ; 40$ cycles of amplification at $95^{\circ} \mathrm{C}$ for $12 \mathrm{sec}$ and $60^{\circ} \mathrm{C}$ for $40 \mathrm{sec}$; and final extension $\left(72^{\circ} \mathrm{C}\right.$ for $\left.5 \mathrm{~min}\right)$. qPCR was performed using the SYBR Green qPCR Detection kit (Tiangen Biotech Co., Ltd.) and the Roche LightCycler 480 Detection system (Roche Diagnostics). Relative mRNA expression levels of $M E G 3$ and TP53 were normalized to the internal reference gene ACTB using the $2^{-\Delta \Delta C a}$ method (23). RT-qPCR was performed in triplicate.

Flow cytometry. Cells were harvested and washed twice in ice-cold PBS for $48 \mathrm{~h}$. Apoptosis was detected by the tagging of membrane phosphatidylserine with the fluorescent dye Annexin V-APC/7AAD Apoptosis Detection kit (Nanjing KeyGEN Biotech, Co. Ltd.) in accordance with the manufacturer's protocols. In each sample, $\sim 5 \times 10^{5}$ cells were analyzed and were immediately subjected to bivariate flow cytometric analysis using a FACScan (BD Biosciences) equipped with CellQuest (version 7.5.3; BD Biosciences).

Morphological analysis of apoptotic cells. Cells were cultured in 24-well plates; after treatment with $\mathrm{H}_{2} \mathrm{O}_{2}$ for $24 \mathrm{~h}$, the cells were stained with $125 \mu 1$ Hoechst 33258 (Sigma-Aldrich; Merck $\mathrm{KGaA}$ ) staining solution at $37^{\circ} \mathrm{C}$ for $5 \mathrm{~min}$, washed twice with PBS, and observed using a fluorescence microscope fitted with a camera (Olympus Corporation; magnification, $\mathrm{x} 400$ ).

Western blot analysis. Cells from each group were lysed using RIPA lysis buffer (Beijing Solarbio Science \& Technology Co., Ltd.). The protein fraction was harvested by centrifugation at $14,000 \mathrm{x} \mathrm{g}$ at $5^{\circ} \mathrm{C}$ for $20 \mathrm{~min}$ and quantified using the BCA protein assay kit (Beijing Solarbio Science \& Technology Co., Ltd.). Equal amounts of protein $(20 \mu \mathrm{g})$ were separated via $10 \%$ SDS-PAGE and electro-transferred onto a polyvinylidene difluoride membrane (EMD Millipore). The membranes were blocked with 5\% nonfat milk in Tris-buffered saline-0.1\% Tween-20 (TBST) at $20^{\circ} \mathrm{C}$ for $2 \mathrm{~h}$. Subsequently, the membranes were incubated overnight at $4^{\circ} \mathrm{Cin}$ with the following primary antibodies in TBST: anti-Bax $(1: 2,000$; cat. no. ab182733; Abcam), anti-Bcl-2 (1:2,000; cat.no. ab182858; Abcam), anti-caspase3 (1:5,000; cat.no. ab32351; Abcam), anti-caspase9 (1:2,000; cat.no. ab202068; Abcam), anti-p53 (1:1,000; cat. no. 2527; Cell Signaling Technology, Inc.) and anti- $\beta$-actin (1:1,000; cat. no. sc-130656; Santa Cruz Biotechnology, Inc.). After three washes with TBST, the membrane was incubated with an anti-rabbit horseradish peroxidase-conjugated secondary antibody (1:2,000; cat. no. 7074; Cell Signaling 
Table I.Primer sequences for reverse transcription-quantitative PCR.

\begin{tabular}{ll}
\hline Gene & \multicolumn{1}{c}{ Primer sequences $\left(5^{\prime} \rightarrow 3^{\prime}\right)$} \\
\hline MEG3 & F: GCTGGGTCGGCTGAAGAAC \\
& R: CGTGGCTGTGGAGGGATTT \\
FP53 & F: ACCACCATCCACTACAACTACAT \\
& R: CAGGACAGGCACAAACACG \\
ACTB & F: CTTAGTTGCGTTACACCCTTTCTTG \\
& R: CTGTCACCTTCACCGTTCCAGTTT
\end{tabular}

F, forward; MEG3, maternally expressed gene 3; R, reverse.

Technology, Inc.) at $20^{\circ} \mathrm{C}$ for $2 \mathrm{~h}$. Protein bands were visualized using a SuperSignal ${ }^{\mathrm{TM}}$ West Pico PLUS Chemiluminescent substrate (Thermo Fisher Scientific, Inc.). Protein expression levels were quantified using Image-Pro Plus software (version 6.0; Media Cybernetics, Inc.).

Statistical analysis. All experiments were performed in triplicate. Continuous variables are presented as the mean \pm SEM values. SPSS version 13.0 software (SPSS, Inc.) was used for statistical analysis. Differences between groups were analyzed using an unpaired Student's t-test. All other analyses were performed using one-way ANOVA and post-hoc analyses were performed using Tukey's multiple comparisons test. $\mathrm{P}<0.05$ was considered to indicate a statistically significance difference.

\section{Results}

$M E G 3$ regulates apoptosis of ADSCs. To investigate the regulatory effect of MEG3 on apoptosis of ADSCs, MEG3 was transfected into ADSCs to obtain a MEG3 overexpression (MEG3-up) group and a MEG3-silenced (MEG3-down) group. Compared with the vector group, the expression of MEG3 was significantly higher in the MEG3-up group as determined by RT-qPCR $(\mathrm{P}<0.01)$. Compared with the NC group, the expression of MEG3 was significantly lower in the MEG3-down group $(\mathrm{P}<0.01)$ (Fig. 1A).

Apoptosis in each group was detected via flow cytometry to analyze the effect of MEG3 expression on apoptosis. The apoptotic rate was $7.04 \pm 1.10 \%$ in the control group, $9.44 \pm 0.52 \%$ in the vector group, $17.91 \pm 2.02 \%$ in the MEG3-up group, $10.28 \pm 1.31 \%$ in the NC group and $6.38 \pm 1.21 \%$ in the MEG3-down group. The apoptotic rate in the MEG3-up group was significantly higher than that in the vector group $(\mathrm{P}<0.01)$ and that of the MEG3-down group was lower than that of the NC group $(\mathrm{P}<0.05)$ (Fig. 1B). These findings indicated that the apoptotic rate of ADSCs was increased and decreased when MEG3 expression levels were increased and decreased, respectively, suggesting that MEG3 expression affects apoptosis of ADSCs.

The mechanism underlying the effect of MEG3 on apoptosis in cells may be associated with p53 regulation by MEG3. To evaluate this hypothesis and explore the mechanism underlying apoptotic regulation in ADSCs by MEG3 in more detail, RT-qPCR analysis was performed for TP53 in each group of cells. Compared with the vector group, the expression of TP53 was significantly higher in the MEG3-up group $(\mathrm{P}<0.01)$. Compared with the $\mathrm{NC}$ group, the expression of TP53 was significantly lower in the MEG3-down group $(\mathrm{P}<0.01)$ (Fig. 1C). These findings indicated that $\mathrm{p} 53$ may be regulated by MEG3, thus influencing apoptosis of ADSCs.

To further assess apoptosis of ADSCs, key proteins in the apoptosis-related cell signaling pathway regulated by p53 were detected via western blotting. Compared with the vector group, Bax was upregulated in the MEG3-up group $(\mathrm{P}<0.01)$, whereas it was downregulated in the MEG3-down group compared with the NC group $(\mathrm{P}<0.01)$. Bcl-2 was downregulated in the MEG3-up group compared with the vector group $(\mathrm{P}<0.01)$, and was upregulated in the MEG3-down group compared with the NC group $(\mathrm{P}<0.05)$. Caspase 3 was upregulated in the MEG3-up group compared with the vector group $(\mathrm{P}<0.01)$, and downregulated in the MEG3-down group compared with the NC group $(\mathrm{P}<0.01)$. Caspase9 was upregulated in the MEG3-up group compared with the vector group $(\mathrm{P}<0.05)$, and downregulated in the MEG3-down group compared with the NC group $(\mathrm{P}<0.01)$ (Fig. 1D). These results agree with the change in p53 expression and suggested that MEG3 regulated apoptosis of ADSCs by regulating $\mathrm{p} 53$, in turn regulating the downstream apoptotic Bcl-2/Bax pathway.

$\mathrm{H}_{2} \mathrm{O}_{2}$-induced apoptosis of ADSCs. To further assess apoptosis of ADSCs under oxidative stress, a cell oxidative stress model was established with $\mathrm{H}_{2} \mathrm{O}_{2}$ to induce apoptosis of ADSCs. To determine the appropriate $\mathrm{H}_{2} \mathrm{O}_{2}$ concentration, ADSCs were first treated with a gradient of $\mathrm{H}_{2} \mathrm{O}_{2}$ and a survival curve of ADSCs was plotted using the MTT assay. The mortality of ADSCs was $50 \%$ at a concentration of $130.6 \mu \mathrm{M} \mathrm{H}_{2} \mathrm{O}_{2}$ (Fig. 2A). Hence, the half maximal inhibitory concentration $\left(\mathrm{IC}_{50}\right)$ was used in the following experiment.

First, the cells were stained with Hoechst 33258 to detect apoptosis of cells under $\mathrm{H}_{2} \mathrm{O}_{2}$-induced oxidative stress. Compared with the control group, the number of apoptotic cells in the $\mathrm{IC}_{50}$ group was markedly increased, as revealed by inverted fluorescence microscopy (Fig. 2B). Furthermore, upon flow cytometric detection, the apoptotic rate of ADSCs in the $\mathrm{IC}_{50}$ group was $43.63 \pm 5.2 \%$, which was significantly higher than that in the control group $(5.64 \pm 1.72 \%$; $\mathrm{P}<0.01)$, suggesting that ADSCs undergo apoptosis during oxidative stress induced by $\mathrm{H}_{2} \mathrm{O}_{2}$ (Fig. 2C).

After confirming the effect of $\mathrm{H}_{2} \mathrm{O}_{2}$ on apoptosis of ADSCs, MEG3 expression was analyzed in ADSCs by RT-qPCR analysis. The results showed that MEG3 was significantly upregulated in the $\mathrm{IC}_{50}$ group compared with the control group under oxidative stress induced by $\mathrm{H}_{2} \mathrm{O}_{2}(\mathrm{P}<0.01$; Fig. 2D). These results suggested that MEG3 may be involved in apoptosis of ADSCs induced by $\mathrm{H}_{2} \mathrm{O}_{2}$ and plays an important regulatory role.

The key proteins associated with apoptosis were detected via western blotting. Under the influence of $\mathrm{H}_{2} \mathrm{O}_{2}, \mathrm{p} 53$, Bax, caspase 3 and caspase 9 were upregulated, whereas Bcl-2 was downregulated in the $\mathrm{IC}_{50}$ group compared with the control group $(\mathrm{P}<0.01$; Fig. $2 \mathrm{E})$, which was associated with MEG3 upregulation upon $\mathrm{H}_{2} \mathrm{O}_{2}$ treatment. 
A

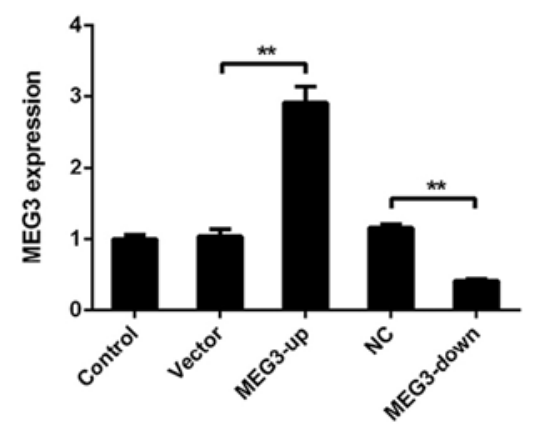

C

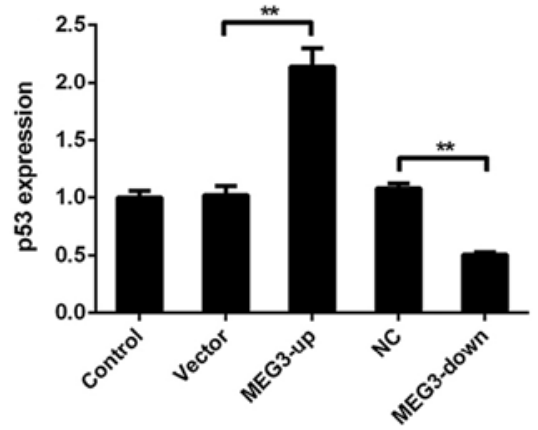

B:
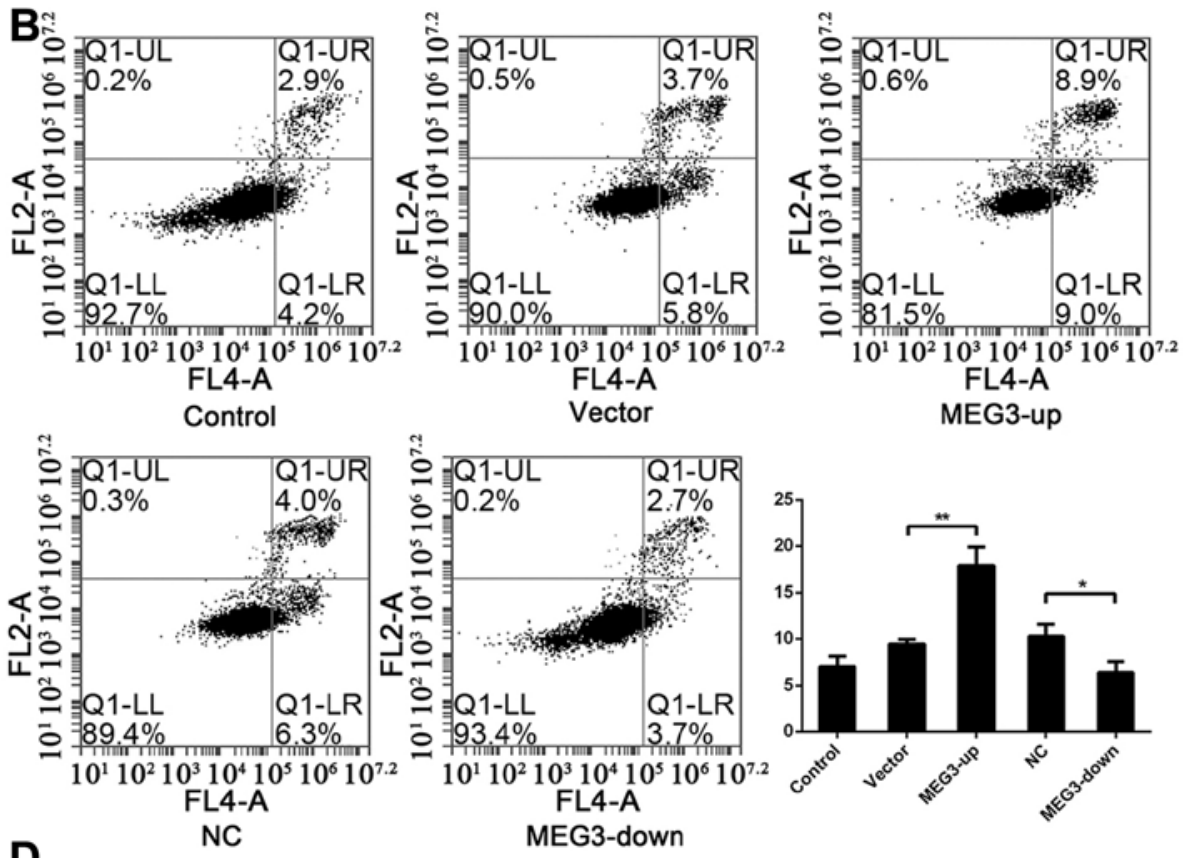

D
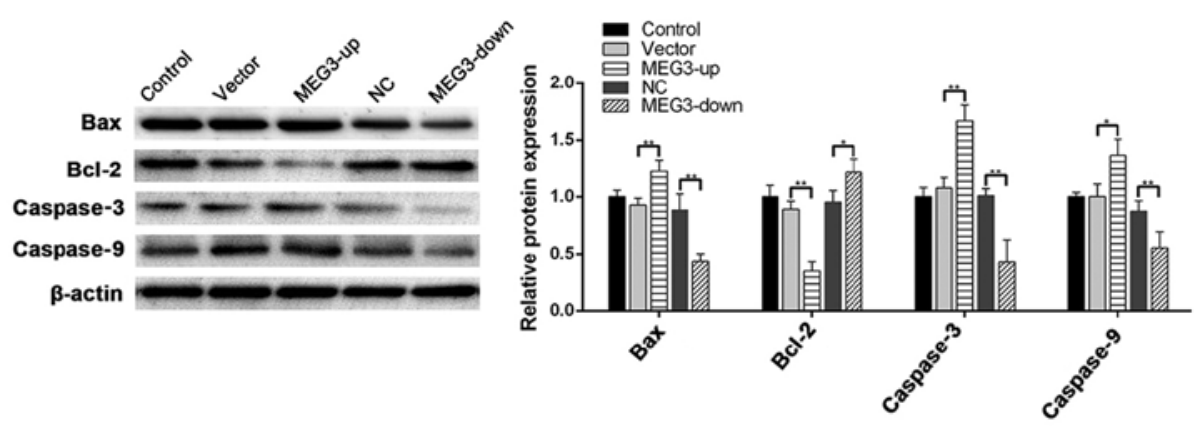

Figure 1. MEG3 regulates apoptosis of ADSCs. (A) After transfecting MEG3 into ADSCs, MEG3 expression in the MEG3-up group was significantly higher than that in the vector group, and MEG3 expression in the MEG3-down group was significantly lower than that in the NC group. (B) Apoptotic rate (UR+LR) was $7.04 \pm 1.10 \%$ in the control group, $9.44 \pm 0.52 \%$ in the vector group, $17.91 \pm 2.02 \%$ in the MEG3-up group, $10.28 \pm 1.31 \%$ in the NC group and $6.38 \pm 1.21 \%$ in the MEG3-down group. The apoptotic rate in the MEG3-up group was significantly higher than that in the vector group, and that in the MEG3-down group was lower than that in the NC group. (C) Compared with the vector group, the expression of p53 was significantly higher in the MEG3-up group. Compared with the NC group, the expression of p53 was significantly lower in the MEG3-down group. (D) Compared with the control group, Bax, caspase 3 and caspase 9 were upregulated in the MEG3-up group. Compared with the NC group, Bax, caspase3 and caspase9 were downregulated in the MEG3-down group. Compared with the vector group, Bcl-2 was downregulated in the MEG3-up group. Compared with the NC group, Bcl-2 was upregulated in the MEG3-down group. "P<0.05, ${ }^{* *} \mathrm{P}<0.01$. ADSC, adipose-derived stem cells; MEG3, maternally expressed gene 3; NC, negative control.

Role of $\mathrm{MEG} 3$ in $\mathrm{H}_{2} \mathrm{O}_{2}$-induced apoptosis. To confirm that MEG3 serves a key role in $\mathrm{H}_{2} \mathrm{O}_{2}$-induced apoptosis of ADSCs, the MEG3-up group, vector group, MEG3-down group and its $\mathrm{NC}$ group were assessed following treatment with $\mathrm{H}_{2} \mathrm{O}_{2}$. As determined by flow cytometry, the apoptotic rates of the vector group, MEG3-up group, NC group and MEG3-down group were $40.93 \pm 1.82,71.53 \pm 2.31,41.13 \pm 4.35$ and $24.09 \pm 2.54 \%$, respectively. MEG3 silencing effectively decreased $\mathrm{H}_{2} \mathrm{O}_{2}$-induced apoptosis in response to the $\mathrm{IC}_{50}$ concentration of $\mathrm{H}_{2} \mathrm{O}_{2}$, and the apoptotic rate in the MEG3-down group was significantly lower than that in the $\mathrm{NC}$ group $(\mathrm{P}<0.01)$. However, upon MEG3 upregulation in the MEG3-up group, apoptotic induction by $\mathrm{H}_{2} \mathrm{O}_{2}$ was significantly greater than that in the vector group $(\mathrm{P}<0.01)$ (Fig. 3A). These data suggested that MEG3 may be the key factor regulating ADSCs apoptosis induced by $\mathrm{H}_{2} \mathrm{O}_{2}$.

To further investigate the mechanism underlying apoptotic regulation by MEG3, western blotting was performed to analyze the expression of related proteins. p53 was significantly downregulated in the MEG3-down group compared with the NC group $(\mathrm{P}<0.01)$, and MEG3 upregulation in the MEG3-up group significantly enhanced p53 compared with in the vector group $(\mathrm{P}<0.01)$. The expression of Bax, caspase 3 and caspase 9 downstream of p53 displayed a similar tendency $(\mathrm{P}<0.01)$. However, $\mathrm{Bcl}-2$ was significantly upregulated in the MEG3-down group compared with the NC group $(\mathrm{P}<0.01$; Fig. 3B). Furthermore, Bcl-2 expression was significantly downregulated in the MEG3-up group compared with the vector group $(\mathrm{P}<0.01 ; \mathrm{Fig} .3 \mathrm{~B})$. These results indicated that $\mathrm{p} 53$ may be regulated by MEG3, and the downstream Bcl-2/Bax signaling pathway could regulate apoptosis of these cells.

\section{Discussion}

In 1893, Neuber first proposed autologous transplantation of adipose tissue for filling (24); since then, autologous 
A

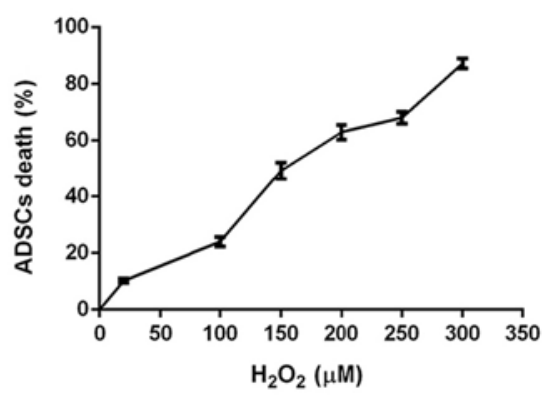

C

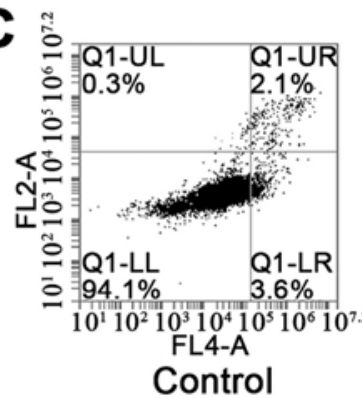

E

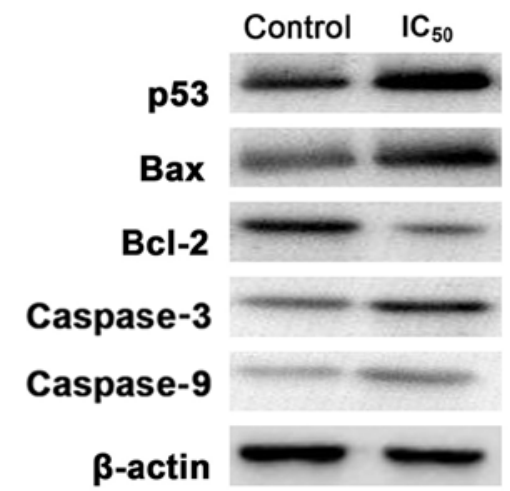

actin
B

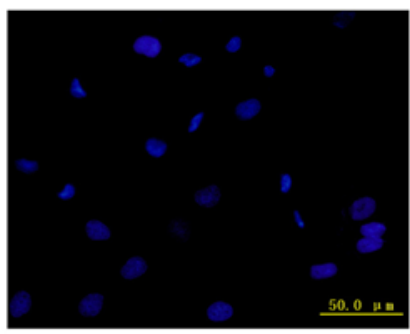

Control
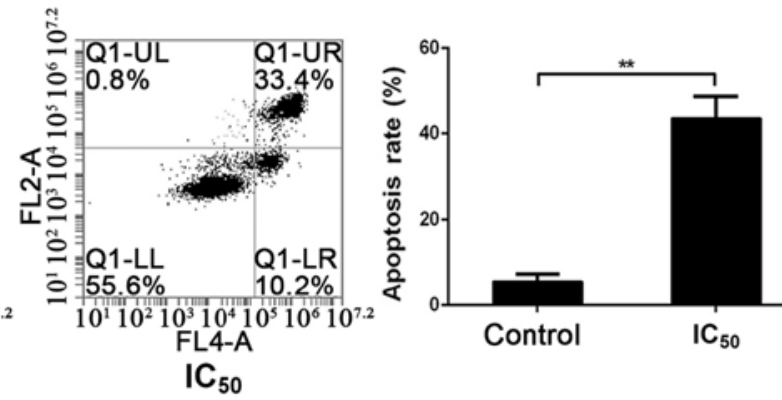

D

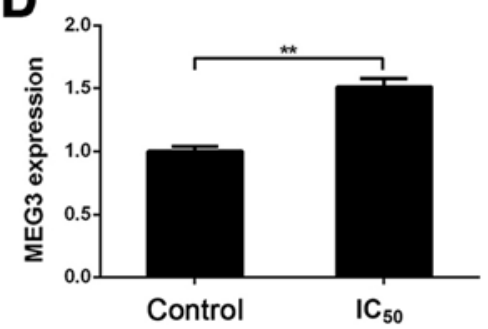

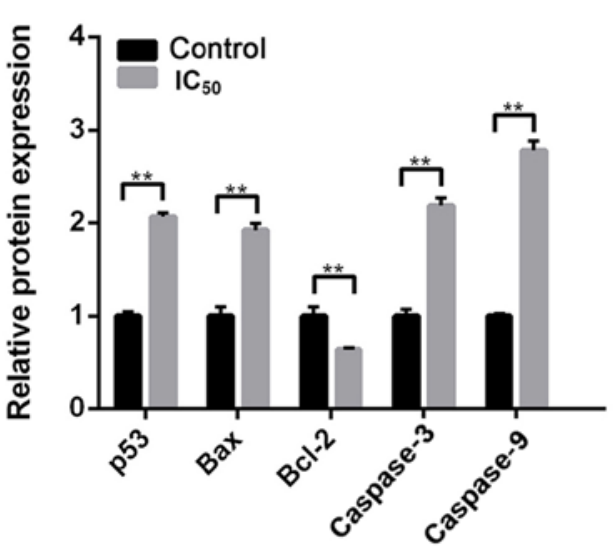

Figure 2. $\mathrm{H}_{2} \mathrm{O}_{2}$-induced apoptosis of ADSCs. (A) After treating ADSCs with a gradient of $\mathrm{H}_{2} \mathrm{O}_{2}$, a survival curve of ADSCs was plotted. The mortality of ADSCs was $50 \%$ at a concentration of $130.6 \mu \mathrm{M} \mathrm{H}_{2} \mathrm{O}_{2}$. (B) Cells were stained with Hoechst 33258 to detect apoptosis. Compared with the control group, the number of apoptotic cells in the $\mathrm{IC}_{50}$ group was increased, as revealed by inverted fluorescence microscopy. (C) Apoptotic rate of ADSCs in the $\mathrm{IC}_{50}$ group was $43.63 \pm 5.2 \%$, which was significantly greater than that in the control group $(5.64 \pm 1.72 \%)$. (D) MEG3 was significantly upregulated in the $\mathrm{IC}_{50}$ group compared with the control group. (E) p53, Bax, caspase 3 and caspase9 were upregulated in the $\mathrm{IC}_{50}$ group compared with the control group. Bcl-2 was downregulated in the $\mathrm{IC}_{50}$ group compared with the control group. ${ }^{* *} \mathrm{P}<0.01$. ADSC, adipose-derived stem cell; $\mathrm{IC}_{50}$, half maximal inhibitory concentration.

transplantation of adipose tissue has improved. This method is increasingly used in plastic surgery, and is considered safe and easy. Subcutaneous adipose tissue in the waist, abdomen and leg are used as donor tissue for autologous transplantation, and these tissues are obtained through vacuum suction and mechanical curettage. Saline washing, static precipitation or low-speed centrifugation are used to improve the purity and cytoactivity of adipose tissue to improve its survival rate. In 2002, Coleman (25) proposed a method for further treating adipose tissue by centrifugation, decanting and wicking to eliminate unviable components and improve the survival rate after transplantation. This method is currently widely used in the clinical setting. In a study using an animal model aimed at improving the survival rate of adipose tissue transplantation, ADSCs were infused into adipose tissue and the cell-assisted lipotransfer method was proposed, which has been applied clinically in recent years $(26,27)$. The important role of
ADSCs in the survival rate of adipose transplantation has been increasingly recognized (28).

IncRNAs were originally considered a type of nonfunctional genetic noise; however, the functions of lncRNA in regulating gene expression, chromatin remodeling, transcription and post-transcriptional processing have been increasingly reported (29). Upregulation of MEG3 has been reported to promote apoptosis in bladder cancer, gastric cancer, lung cancer, osteosarcoma and other cells (23,30-32). In ADSCs, MEG3 overexpression significantly increased the apoptotic rate of ADSCs, whereas MEG3 silencing significantly decreased the apoptotic rate of ADSCs, thus confirming that MEG3 significantly contributes to apoptosis of ADSCs.

MEG3 regulates cellular physiology by regulating p53 and downstream signaling $(23,32)$. RT-qPCR analysis of the regulatory association in ADSCs revealed that $\mathrm{p} 53$ expression levels were positively associated with MEG3 expression levels. 

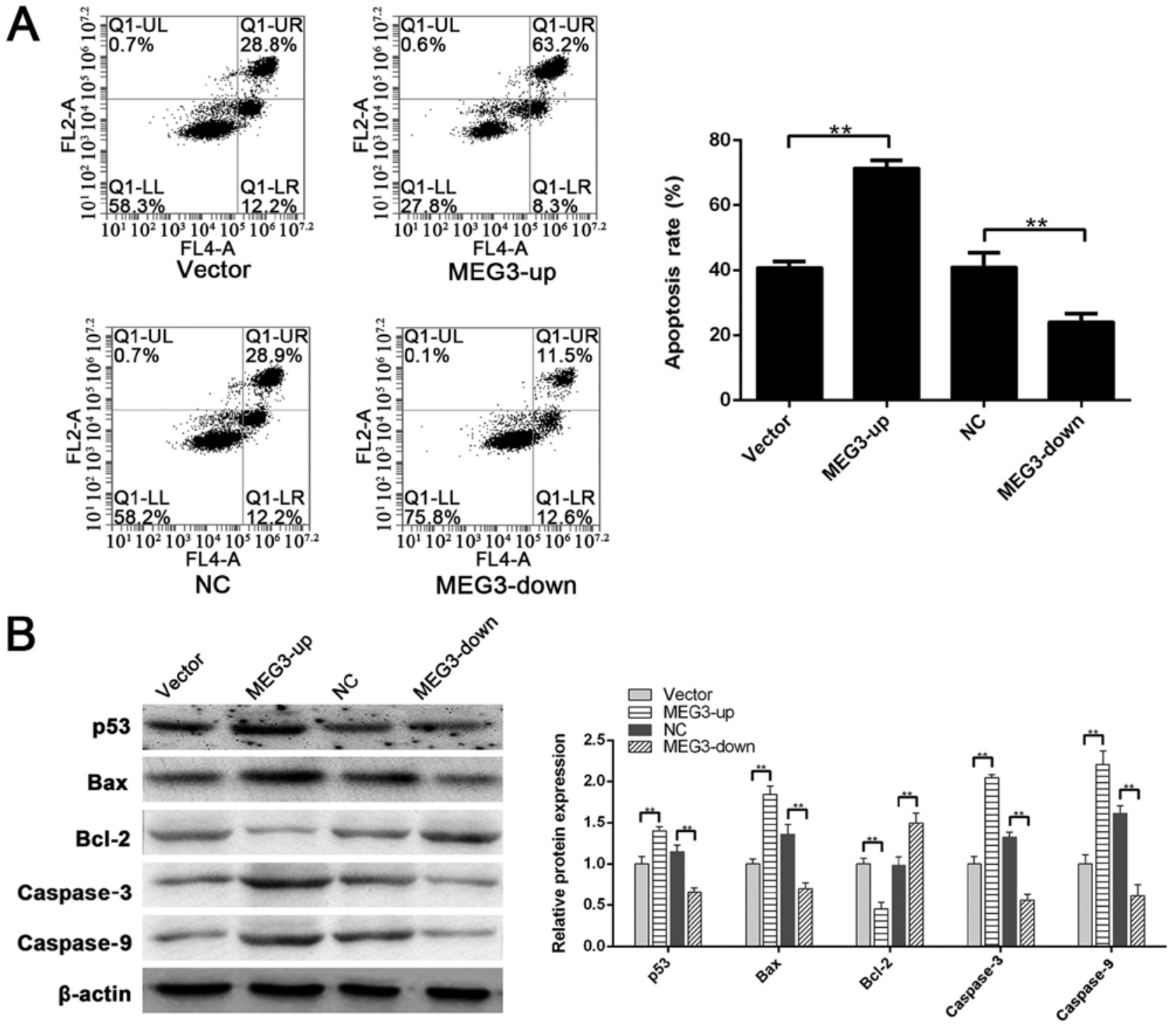

Figure 3. Role of MEG3 in $\mathrm{H}_{2} \mathrm{O}_{2}$-induced apoptosis. (A) Apoptotic rates of the vector group, MEG3-up group, NC group and MEG3-down group were $40.93 \pm 1.82,71.53 \pm 2.31,41.13 \pm 4.35$ and $24.09 \pm 2.54 \%$, respectively. Apoptotic rate in the MEG3-up group was significantly greater than that in the vector group. Apoptotic rate in the MEG3-down group was significantly lower than that in the NC group. (B) Compared with the vector group, the expression of p53, Bax, caspase3 and caspase9 was significantly higher in the MEG3-up group. Compared with the NC group, the expression of p53, Bax, caspase3 and caspase9 was significantly lower in the MEG3-down group. Compared with the vector group, Bcl-2 was downregulated in the MEG3-up group. Compared with the NC group, Bcl-2 was upregulated in the MEG3-down group. ${ }^{* *} \mathrm{P}<0.01$. MEG3, maternally expressed gene 3; $\mathrm{NC}$, negative control.

Furthermore, western blotting indicated that the Bcl-2/Bax pathway downstream of p53 may regulate apoptosis. When MEG3 was upregulated, p53 and Bax were upregulated, whereas Bcl-2 protein expression was suppressed, thus promoting apoptosis.

During adipose tissue transplantation, currently used methods for obtaining adipose tissue often result in the incorporation of numerous damaged and dead cells in the tissue; in addition, after transplantation, the microvascular system in the tissue has not formed yet and the cells are in a state of ischemia and anoxia $(18,33)$. These conditions subject transplanted ADSCs to oxidative stress, thus increasing reactive oxygen species production in cells and inducing apoptosis. A reduction in the survival rate of ADSCs directly affects the survival rate of transplanted tissue (33). In the present study, oxidative stress was induced in ADSCs with $\mathrm{H}_{2} \mathrm{O}_{2}$, thus increasing the apoptotic rate of ADSCs. Furthermore, RT-qPCR analysis revealed that MEG3 was upregulated, suggesting that MEG3 may contribute to apoptosis induced by oxidative stress in ADSCs. After overexpression and silencing of MEG3 in ADSCs, the apoptotic rate of ADSCs induced by $\mathrm{H}_{2} \mathrm{O}_{2}$ was assessed. MEG3 silencing decreased apoptotic induction by $\mathrm{H}_{2} \mathrm{O}_{2}$, whereas MEG3 overexpression aggravated apoptosis. Detection of pathway proteins via western blotting revealed that p53 was regulated by MEG3 and in turn regulated apoptosis of ADSCs through the Bcl-2/Bax pathway.

In conclusion, the present results revealed that MEG3 significantly contributed to spontaneous apoptosis of ADSCs and apoptosis induced by oxidative stress. This effect was regulated by MEG3 and it was suggested that p53 may modulate the downstream $\mathrm{Bcl}-2 / \mathrm{Bax}$ pathway. The present results highlight the role of MEG3 in apoptosis of ADSCs and provide a foundation for further improving the survival rate of ADSCs. Future work to further verify the mechanism of apoptosis 
underlying ADSCs in vivo and in vitro should be conducted to lay a foundation for future clinical research. These results may be useful for improving the survival rate of adipose tissue grafts and surgical effects, as well as the success rate of plastic surgery for filling with adipose tissue.

\section{Acknowledgements}

Not applicable.

\section{Funding}

The present study was supported by the Youth Backbone Support Project of China Medical University (grant no. QGZD2018025).

\section{Availability of data and materials}

The datasets used and/or analyzed during the present study are available from the corresponding author on reasonable request.

\section{Authors' contributions}

YS designed the study, performed the research, analyzed data and wrote the paper. The author read and approved the final manuscript.

\section{Ethics approval and consent to participate}

Not applicable.

\section{Patient consent for publication}

Not applicable.

\section{Competing interests}

The author declares that they have no competing interests.

\section{References}

1. Rohrich RJ: The American Society of Plastic Surgeons' procedural statistics: What they really mean. Plast Reconstr Surg 112: 1389-1392, 2003

2. Claro F Jr, Figueiredo JC, Zampar AG and Pinto-Neto AM: Applicability and safety of autologous fat for reconstruction of the breast. Br J Surg 99: 768-780, 2012.

3. Wang CF, Zhou Z, Yan YJ, Zhao DM, Chen F and Qiao Q: Clinical analyses of clustered microcalcifications after autologous fat injection for breast augmentation. Plast Reconstr Surg 127: 1669-1673, 2011.

4. Coleman SR: Structural fat grafting: More than a permanent filler. Plast Reconstr Surg 118 (3 Suppl): S108-S120, 2006.

5. Lu F, Li J, Gao J, Ogawa R, Ou C, Yang B and Fu B: Improvement of the survival of human autologous fat transplantation by using VEGF-transfected adipose-derived stem cells. Plast Reconstr Surg 124: 1437-1446, 2009.

6. Kirkham JC, Lee JH, Medina MA III, McCormack MC, Randolph MA and Austen WG Jr: The impact of liposuction cannula size on adipocyte viability. Ann Plast Surg 69: 479-481, 2012.

7. Nguyen A, Pasyk KA, Bouvier TN, Hassett CA and Argenta LC: Comparative study of survival of autologous adipose tissue taken and transplanted by different techniques. Plast Reconstr Surg 85: 378-389, 1990
8. Billings E Jr and May JW Jr: Historical review and present status of free fat graft autotransplantation in plastic and reconstructive surgery. Plast Reconstr Surg 83: 368-381, 1989.

9. Pal R, Venkataramana NK, Bansal A, Balaraju S, Jan M, Chandra R, Dixit A, Rauthan A, Murgod U and Totey S: Ex vivo-expanded autologous bone marrow-derived mesenchymal stromal cells in human spinal cord injury/paraplegia: A pilot clinical study. Cytotherapy 11: 897-911, 2009.

10. Zuk PA: The adipose-derived stem cell: Looking back and looking ahead. Mol Biol Cell 21: 1783-1787, 2010.

11. Ionescu L, Byrne RN, van Haaften T, Vadivel A, Alphonse RS, Rey-Parra GJ, Weissmann G, Hall A, Eaton F and Thébaud B: Stem cell conditioned medium improves acute lung injury in mice: In vivo evidence for stem cell paracrine action. Am J Physiol Lung Cell Mol Physiol 303: L967-L977, 2012.

12. Fouraschen SM, Pan Q, de Ruiter PE, Farid WR, Kazemier G, Kwekkeboom J, Ijzermans JN, Metselaar HJ, Tilanus HW, de Jonge $\mathbf{J}$ and van der Laan LJ: Secreted factors of human liver-derived mesenchymal stem cells promote liver regeneration early after partial hepatectomy. Stem Cells Dev 21: 2410-2419, 2012.

13. Zuk PA, Zhu M, Mizuno H, Huang J, Futrell JW, Katz AJ, Benhaim P, Lorenz HP and Hedrick MH: Multilineage cells from human adipose tissue: Implications for cell-based therapies. Tissue Eng 7: 211-228, 2001.

14. Kern S, Eichler H, Stoeve J, Klüter H and Bieback K: Comparative analysis of mesenchymal stem cells from bone marrow, umbilical cord blood, or adipose tissue. Stem Cells 24: 1294-1301, 2006.

15. Su M, Guan H, Zhang F, Gao Y, Teng X and Yang W: HDAC6 regulates the chaperone-mediated autophagy to prevent oxidative damage in injured neurons after experimental spinal cord injury. Oxid Med Cell Longev 2016: 7263736, 2016.

16. Chen X, Yan L, Guo Z, Chen Z, Chen Y, Li M, Huang C, Zhang X and Chen L: Adipose-derived mesenchymal stem cells promote the survival of fat grafts via crosstalk between the Nrf2 and TLR4 pathways. Cell Death Dis 7: e2369, 2016.

17. Zhang X, Rice K, Wang Y, Chen W, Zhong Y, Nakayama Y, Zhou Y and Klibanski A: Maternally expressed gene 3 (MEG3) noncoding ribonucleic acid: Isoform structure, expression, and functions. Endocrinology 151: 939-947, 2010.

18. Luo G, Wang M, Wu X, Tao D, Xiao X, Wang L, Min F, Zeng F and Jiang G: Long non-coding RNA MEG3 inhibits cell proliferation and induces apoptosis in prostate cancer. Cell Physiol Biochem 37: 2209-2220, 2015.

19. Peng W, Si S, Zhang Q, Li C, Zhao F, Wang F, Yu J and Ma R: Long non-coding RNA MEG3 functions as a competing endogenous RNA to regulate gastric cancer progression. J Exp Clin Cancer Res 34: 79, 2015.

20. Zhang X, Zhou Y, Mehta KR, Danila DC, Scolavino S, Johnson SR and Klibanski A: A pituitary-derived MEG3 isoform functions as a growth suppressor in tumor cells. J Clin Endocrinol Metab 88: 5119-5126, 2003.

21. Lu KH, Li W, Liu XH, Sun M, Zhang ML, Wu WQ, Xie WP and Hou YY: Long non-coding RNA MEG3 inhibits NSCLC cells proliferation and induces apoptosis by affecting p53 expression. BMC Cancer 13: 461, 2013.

22. Zhou Y, Zhong Y, Wang Y, Zhang X, Batista DL, Gejman R, Ansell PJ, Zhao J, Weng C and Klibanski A: Activation of p53 by MEG3 non-coding RNA. J Biol Chem 282: 24731-24742, 2007.

23. Livak KJ and Schmittgen TD: Analysis of relative gene expression data using real-time quantitative PCR and the 2(-Delta Delta C(T)) method. Methods 25: 402-408, 2001.

24. Neuber F: Fettransplantation. Chir Kongr Verhandl Dsch Gesellch Chir 22: 66, 1893.

25. Coleman SR: Hand rejuvenation with structural fat grafting. Plast Reconstr Surg 110: 1731-1747, 2002.

26. Matsumoto D, Sato K, Gonda K, Takaki Y, Shigeura T, Sato T, Aiba-Kojima E, Iizuka F, Inoue K, Suga $\mathrm{H}$ and Yoshimura K: Cell-assisted lipotransfer: Supportive use of human adipose-derived cells for soft tissue augmentation with lipoinjection. Tissue Eng 12: 3375-3382, 2006.

27. Moseley TA, Zhu M and Hedrick MH: Adipose-derived stem and progenitor cells as fillers in plastic and reconstructive surgery. Plast Reconstr Surg 118 (3 Suppl): S121-S128, 2006.

28. Toyserkani NM, Quaade ML and Sørensen JA: Cell-Assisted Lipotransfer: A systematic review of its efficacy. Aesthetic Plast Surg 40: 309-318, 2016.

29. Ponting CP, Oliver PL and Reik W: Evolution and functions of long noncoding RNAs. Cell 136: 629-641, 2009. 
30. Ying L, Huang Y, Chen H, Wang Y, Xia L, Chen Y, Liu Y and Qiu F: Downregulated MEG3 activates autophagy and increases cell proliferation in bladder cancer. Mol Biosyst 9: 407-411, 2013

31. Sun M, Xia R, Jin F, Xu T, Liu Z, De W and Liu X: Downregulated long noncoding RNA MEG3 is associated with poor prognosis and promotes cell proliferation in gastric cancer. Tumour Biol 35: 1065-1073, 2014

32. Shi Y, Lv C, Shi L and Tu G: MEG3 inhibits proliferation and invasion and promotes apoptosis of human osteosarcoma cells. Oncol Lett 15: 1917-1923, 2018.
33. Carrière A,Ebrahimian TG, Dehez S, Augé N, Joffre C, André M, Arnal S, Duriez M, Barreau C, Arnaud E, et al: Preconditioning by mitochondrial reactive oxygen species improves the proangiogenic potential of adipose-derived cells-based therapy. Arterioscler Thromb Vasc Biol 29: 1093-1099, 2009.

This work is licensed under a Creative Commons Attribution-NonCommercial-NoDerivatives 4.0 International (CC BY-NC-ND 4.0) License. 